\title{
Biologi Mangrove Ditinjau dari Nilai Penting Keanekaragaman, Dominansi, Keragaman Di Pesisir Kecamatan Bonang, Demak
}

\author{
Bima Agung Saputra*, Rudhi Pribadi, Chrisna Adhi Suryono \\ Departemen IImu Kelautan, Fakultas Perikanan dan IImu Kelautan, Universitas Diponegoro \\ JI. Prof.H.Soedarto S.H, Tembalang,Semarang, Jawa Tengah 50275 Indonesia \\ *Corresponding author, e-mail : bimaagungsaputra263@gmail.com
}

\begin{abstract}
ABSTRAK: Penelitian mengenai kajian kawasan kawasan rehabilitasi mangrove ini dilakukan di Desa Morodemak dan Desa Purworejo, Kecamatan Bonang, Kabupaten Demak. Tujuan penelitian ini untuk mengetahui kondisi eksisting struktur dan komposisi vegetasi mangrove serta mengkaji kegiatan rehabilitasi mangrove di Desa Morodemak dan Desa Purworejo, Kecamatan Bonang, Kabupaten Demak. Metode Penelitian yang digunakan adalah metode deskriptif eksploratif dengan analisa data struktur dan komposisi vegetasi mangrove dan presentasi peran masyarakat dan peran lembaga pemerintah/non pemerintah setempat. Hasil penelitian di Desa Morodemak dan Desa Purworejo ditemukan 9 spesies mangrove dari tiga komponen vegetasi yaitu mayor, minor dan asosiasi. Secara umun kerapatan kategori pohon (tree) di Lokasi I 3211 ind/ha, sementara di Lokasi II 3611 ind/ha. Kerapatan kategori anakan (sapling) di Lokasi I 533 ind/ha, sementara di Lokasi II ind/ha. Kerapatan kategori semai (seedling) di Lokasi I 450 ind/ha sementara di Lokasi II $1383 \mathrm{ind} / \mathrm{ha}$. Peran masyarakat dan peran lembaga pemerintah/non pemerintah di Desa Purworejo lebih aktif jika dibandingkan Desa Morodemak.
\end{abstract}

Kata kunci: Mangrove, Komposisi, Rehabilitasi, Morodemak, Purworejo

\section{Mangrove from the Important Value of Diversity, Dominance, Diversity in the Coastal District of Bonang, Demak}

ABSTRACT: Research on the study of mangrove rehabilitation in Morodemak and Purworejo Village, Bonang District, Demak Regency. The purpose of this study to determine the existing conditions of the structure and composition of mangrove vegetation and to study the rehabilitation activities of mangroves in Morodemak and Purworejo Villages, Bonang District, Demak Regency. The research method used is descriptive method with exploratory data analysis mangrove vegetation structure, composition and presentase the role of society and the role of government institution. The results of the research in Morodemak and Purworejo Villages found 9 mangrove species from three vegetation components, namely major, minor and association. In general, the tree density in location I has an average of 3211 ind/ha, while in Location II is 3611 ind/ha. Sapling density at Location I averages 533 ind/ha, while in Location II the average is 1422 ind / ha. The seedling category density at Location I has an average of 450 ind/ha while in Location II an average of $1383 \mathrm{ind} / \mathrm{ha}$. The role of the community and the role of government in Purworejo Village is more active than Morodemak Village.

Keywords: Mangrove, Composition, Rehabilition, Morodemak Village, Purworejo Village

\section{PENDAHULUAN}

Mangrove merupakan sebutan umum untuk menggambarkan varietas komunitas pantai tropis yang didominasi oleh beberapa jenis pohon dan semak yang mempunyai kemampuan beradaptasi dalam perairan asin, tipe hutan ini secara teratur tergenang dan dipengaruhi oleh pasang surut air laut. Ekosistem mangrove ditengah-tengah kehidupan manusia memberikan beberapa manfaat yang bersifat langsung maupun tidak langsung (Ditjen KPPPK, 2005).

Namun pada kenyataannya luas hutan mangrove semakin berkurang, menurut Tarigan (2008) hal tersebut bisa terjadi seiring dengan pesatnya kebutuhan masyarakat, serta meningkatnya pembangunan dikawasan pesisir salah satunya Pantai Utara Jawa (Pantura). 
Kondisi ini diperparah dengan keberadaan ancaman lain dari manusia, seperti limbah pabrik, sampah (IUCN, 2006) dan reklamasi (Setyawan dan Winarno, 2006) maupun dari alam seperti penurunan tanah, kenaikan muka air laut (Wirasatriya et al., 2006) dan erosi (Diposaptono, 2010), sehingga menimbulkan degradasi ekosistem semakin meningkat.Pada dasarnya hutan mangrove dapat pulih melalui regenerasi secara alami yaitu dengan buah atau propagul yang jatuh disekitar pohon mangrove yang akan tumbuh menjadi anakan mangrove dan pada akhirnya menjadi pohon mangrove. Tetapi laju kerusakan mangrove lebih cepat dan tidak diimbangi dengan laju kecepatan pemulihan secara alami terutama jika terjadi perubahan kondisi fisik habitat ke arah tidak normal dan perubahan pada sistem hidrologi.

Begitu besarnya manfaat dan banyaknya penyebab degradasi ekosistem mangrove, salah satu upaya pelestarian ekosistem lingkungan pesisir yang penting, dimana dalam komponen ada 2 hal penting yaitu rehabilitasi dan perlindungan. Untuk keberhasilan rehabilitasi mangrove tersebut perlu dilakukan suatu kajian untuk mengetahui kondisi tapak dalam upaya pra rehabilitasi sebagai langkah awal dalam upaya rehabilitasi yang berkelanjutan dan terpadu terciptanya ekosistem mangrove yang lestari di masa yang akan datang. Tujuan penelitian ini untuk mengetahui kondisi mangrove yang ada di pesisir Bonang, Kabupaten Demak.

\section{MATERI DAN METODE}

Materi yang digunakan dalam Penelitian ini adalah data primer dan data sekunder yang berhubungan dengan kegiatan rehabilitasi mangrove di Desa Morodemak dan Desa Purworejo, Kecamatan Bonang, Kabupaten Demak. Selanjutnya data primer dalam penelitian ini diperoleh melalui survei langsung ke lapangan. Data-data meliputi kondisi fisik mangrove, data kualitas lingkungan (salinitas, suhu, $\mathrm{pH}$ ), sedimen (kandungan bahan organik, dan ukuran butir), data sosial-ekonomi masyarakat (data penduduk dan pekerjaan), data lembaga dan peran lembaga daerah setempat, dan data persepsi, partisipasi, dan aspirasi masyarakat dalam kegiatan rehabilitasi mangrove. Data sekunder yang merupakan data pendukung ini diperoleh dengan melakukan studi berbagai pustaka seperti hasil-hasil penelitian terdahulu dan tulisan-tulisan yang relavan dengan permasalahan yang diteliti. Data-data tersebut meliputidata curah hujan, data oseanografi (gelombang dan pasang surut), data kerusakan pantai, dan data peraturan perundangan.

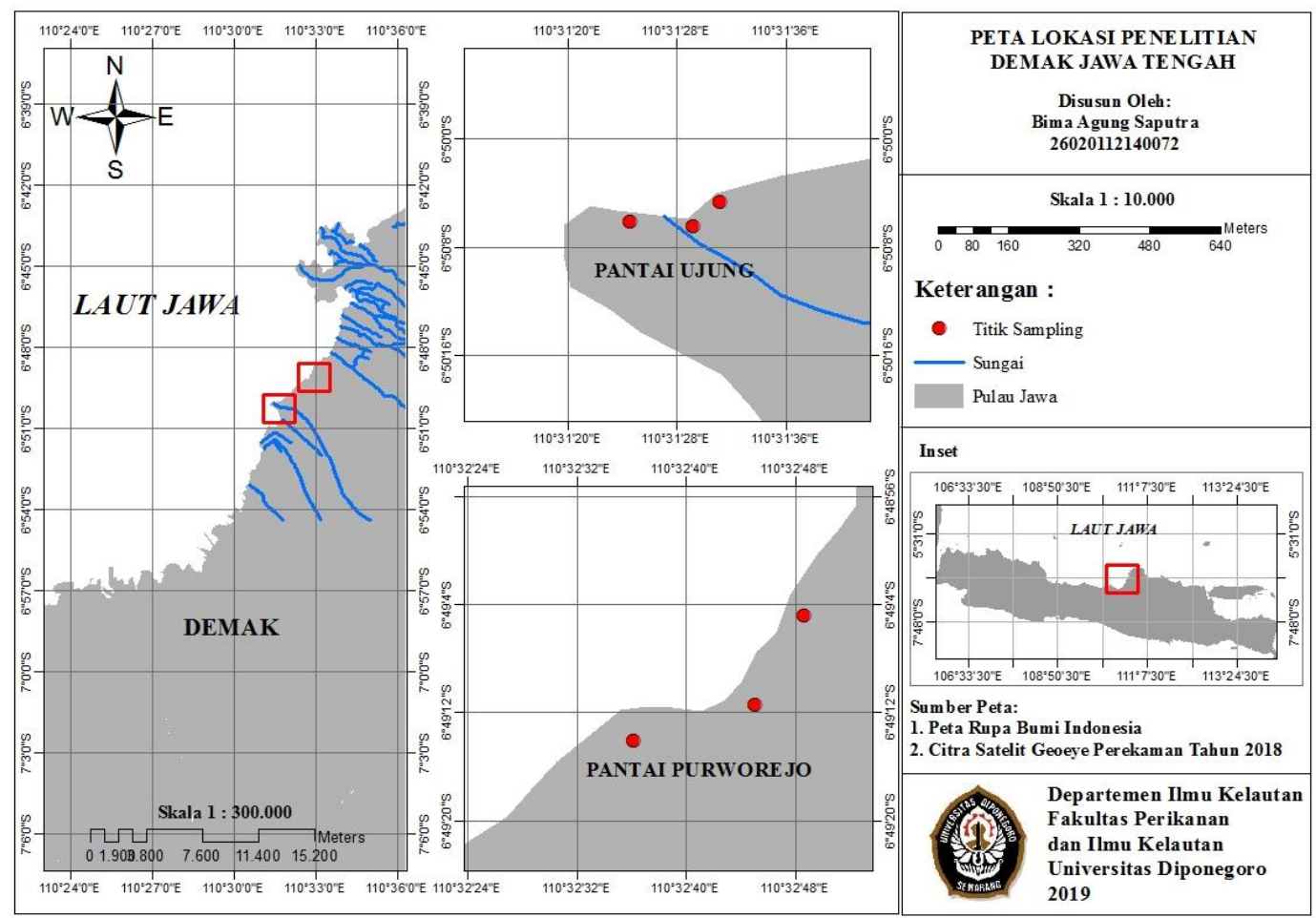


Gambar 1. Peta Lokasi Penelitian

Metode penentuan lokasi titik sampling yang digunakan adalah metode stratified random sampling. Pengambilan data vegetasi mangrove dengan menggunakan plot, dimana Plot $10 \times 10 \mathrm{~m}$ di dalamnya dibuat subplot $5 \mathrm{~m} \times 5 \mathrm{~m}$ dan di dalam subplot $5 \mathrm{~m} \times 5 \mathrm{~m}$ dibuat subplot $1 \times 1 \mathrm{~m}$ yang posisinya pada masing-masing plot sudah ditetapkan pada sudut yang sama untuk mendapatkan sampel yang random/acak. Jumlah responden sebanyak 60 orang (Desa Morodemak 30 Orang dan Desa Purworejo 30 orang). Jumlah tersebut ditentukan berdasarkan Renta et al. (2016) dimana untuk metode deskriptif jumlah responden yang diambil adalah minimal $10 \%$ dari populasi.

Kerapatan adalah jumlah individu per unit area (Mueller-Dumbois dan Ellenberg, 1974). Nilai kerapatan yang dihitung memiliki satuan ind/ha, menggunakan rumus:

$$
\text { Kerapatan }=\frac{\text { Jumlah individu dari suatu spesies dalam seluruh plot }}{\text { Luas Pot }}
$$

Kerapatan relatif merupakan persentase kerapatan masing-masing spesies dalam transek (Mueller-Dumbois dan Ellenberg, 1974). Nilai kerapatan relative didapatkan dengan menggunakan rumus :

$$
\text { Kerapatan Relatif }=\frac{\text { Kerapatan suatu jenis }- \text { jenis }}{\text { Jumlah } \text { kerapatan seluruh jenis }} \times 100 \%
$$

Basal area merupakan penutupan areal hutan mangrove oleh batang pohon. Basal area didapatkan dari pengukuran batang pohon secara melintang. Diameter batang tiap spesies tersebut kemudian diubah menjadi basal area dengan menggunakan rumus :

$$
\mathrm{BA}=\frac{\pi \cdot D^{2}}{4} \mathrm{~cm}^{2}
$$

Keterangan $: \mathrm{BA}=$ Basal Area; $\pi=3,14 ; \quad \mathrm{D}=$ Diameter batang

Dominansi relatif merupakan persentase penutupan suatu spesies terhadap suatu areal mangrove yang didapatkan dari nilai basal area untuk spesies pohon dan sapling, menggunakan rumus :

$$
\text { Dominasi Relatif }=\frac{\text { Jumlah basal area suatu spesies }}{\text { Area cuplikan atau luas contoh }} \times 100 \%
$$

Sedangkan seedling nilai dominansi relative diperoleh daripersentase penutupan spesies terhadap subplot $1 \mathrm{~m} \times 1 \mathrm{~m}$ dengan rumus :

$$
\text { Dominasi Relatif }=\frac{\text { Total prosentase penutupan suatu spesies }}{\text { Total prosentase penutupan semua spesies }} \times 100 \%
$$

Nilai penting diperoleh untuk mengetahui spesies yang mendominasi di suatu areal mangrove. Nilai penting ini didapat dengan menjumlahka nnilai kerapatan relative dan dominansi relatif (Soerinaga dan Indrawan, 1982)

$$
\mathrm{INP}=\mathrm{KR}+\mathrm{DR}
$$

Keterangan : Dimana, NP $=$ Nilai Penting; $K R=$ Kerapatan Relatif; $D R=$ Dominansi Relatif

Segitiga Shepard yang digunakan dalam klasifikasi jenis sedimen merupakan pembagian atas tiga jenis sedimen, yaitu pasir, lanau, dan lempung. Metode segitiga Shephard lebih sesuai digunakan untuk klasifikasi pada sampel dengan ukuran butiran yang cenderung kecil 
dibandingkan dengan metode segitiga Folk. Penentuan kategori kandungan bahan organik didasarkan pada Landon (1991), dimana kandungan bahan organik $\leq 2 \%$ : sangat rendah; $2,1 \%$ 4\%: rendah; 4,1\% - 10\%: sedang; 10,1\% - 20\%: Tinggi; > 20\%: sangat tinggi. Untuk analisa kandungan bahan organik dilakukan dengan metode Loss on Ignition (LOI). Adapun tahapan analisis kandungan bahan organik menggunakan metode LOI berdasarkan prosedur laboratorium Universitas of Pittsburg dan ketetapan Allen et al., (1974) sebagai berikut :

$$
\mathrm{Li}=\frac{W o-W t}{W o} \times 100 \%
$$

\section{HASIL DAN PEMBAHASAN}

Hasil penelitian ditemukan 9 spesies mangrove, 6 spesies ditemukan di dalam plot pengambilan data penelitian yaitu Avicennia marina, Avicennia alba, Bruguiera cylindrica, Rhizophora mucronata, Rhizophora apiculate, Xylocarpus molluccensis, Acanthus ilicifolius, Talipariti tiliaceum dan Millettia pinnata. Sementara untuk spesies - spesies yang lain ditemukan diluar plot pengambilan data. Pengidentifikasian spesies dilakukan secara insitu yang mengacu pada Kitamura et al., (1997). Apabila terdapat keragu - raguan dalam identifikasi secara langsung, maka akan dilakukan identifikasi lanjutan yang mengacu kepada Tomlinson (1994). Spesies mangrove yang ditemukan dalam penelitian merupakan spesies yang masuk kedalam 3 komponen ekosistem mangrove yaitu komponen mayor, minor dan asosiasi.

Hasil penelitian mengenai struktur vegetasi mangrove di Desa Morodemak dan Desa Purworejo, Kecamatan Bonang, Kabupaten Demak, secara keseluruhan menunjukkan bahwa area ini didominasi oleh 2 spesies yaitu Avicennia marina dan Rhizophora mucronata. Hal ini ditunjukkan dengan tingginya indeks nilai penting (INP) setiap spesies tersebut pada masing masing lokasi dan dominansinya pada semua kategori pertumbuhan (pohon, anakan dan semai).Berdasarkan kategori pertumbuhan, pada Lokasi I rata - rata kerapatan mangrove kategori pohon lebih tinggi dibandingkan dengan kategori anakan ataupun semai. Sementara pada Lokasi II rata - rata kerapatan mangrove kategori pohon juga lebih tinggi dibandingkan dengan kategori anakan atau semai. Di Desa Morodemak kerapatan kategori pohon berkisar antara 1967- 4433 ind/ha, kategori anakan (sapling) berkisar antara 89-844 in/ha dan kategori semai (seedling) berkisar antara 300-550 ind/ha. Sementara di Desa Purworejo kerapatan kategori pohon berkisar antara 3033-3933 ind/ha, kategori anakan (sapling) berkisar antara 1200-1644 ind/ha dan kategori semai (seedling) berkisar antara 100-3300 ind/ha.

Diameter batang pohon diekosistem mangrove Desa Morodemak (Lokasi I) berdiameter rata - rata kecil sampai besar karena ditemukan di setiap titik penelitian dengan kisaran diameter antara $<80 \mathrm{~cm}$ sampai dengan $\geq 240 \mathrm{~cm}$, spesies yang mendominasi dalam distribusi diameter batang pohon di Lokasi I, pada titik MD I dan MD III yaitu Rhizophora mucronata, sedangkan pada titik MD II spesies yang mendominasi yaitu Rhizophora apiculata. Di semua titik diameter batang mangrove yaitu kelas $<80 \mathrm{~cm}$. Sedangkan Lokasi II berbeda dengan Lokasi I Distribusi diameter batang pohon di ekosistem mangrove Desa Purworejo Lokasi II) di semua titik PR I, PR II, PR III didominasi oleh kelas diameter $<80 \mathrm{~cm}$. Penyebaran distribusi batang pohon pada ekosistem mangrove di Desa Purworejo (Lokasi II) pada kelas $80-<160 \mathrm{~cm}$ tersebar merata pada semua titik, namun pada kelas $160-<240 \mathrm{~cm}$ hanya ditemukan di titik PR I. Sedangkan untuk kelas $\geq 240 \mathrm{~cm}$ tidak ditemukan sama sekali di semua titik.

Secara umum, di setiap lokasi di Desa Morodemak dan Desa Purworejo, Kecamatan Bonang didominasi oleh empat kelas yang berbeda yaitu $\leq 6 \mathrm{~m}, 6-<10 \mathrm{~m}$ dan $10-<14 \mathrm{~m}$ dan $\geq 14$ m. Di ekosistem mangrove Desa Morodemak (Lokasi I) pada titik MD I kelas 10-<14 m merupakan kelas yang paling dominan, pada titik MD II tinggi pohon lebih didominasi oleh kelas $\geq 14 \mathrm{~m}$. Sedangkan pada titik MD III tinggi pohon didominasi oleh kelas $6-<10 \mathrm{~m}$, kelas $\leq 6 \mathrm{~m}$ tersebar merata ditemukan disemua titik namun tidak ada yang mendominasi pada setiap titiknya. Sedangkan di ekosistem mangrove Desa Purworejo (Lokasi II) kelas $\leq 6 \mathrm{~m}$ merupakan kelas yang paling dominan karena ditemukan di semua titik ditemukan mangrove yang memiliki tinggi yang masuk kedalam kelas tersebut, namun pada titik PR I yang paling dominan yaitu kelas $6-<10 \mathrm{~m}$. 
Kelas 10-<14 m juga ditemukan di semua titik PR I, PR II dan PR III namun jumlahnya sedikit. Sedangkan pada Kelas $\geq 14 \mathrm{~m}$ tidak ditemukan di semua titik.

\section{KESIMPULAN}

Komposisi mangrove di Desa Morodemak dan Desa Purworejo di temukan 9 spesies mangrove. Spesies dalam kategori mayor ditemukan 5 spesies, kategori minor 1 spesies dan asosiasi 3 spesies. Kerapatan rata-rata pohon yang ada di ekosistem mangrove di Desa Morodemak sebesar 3211 ind/ha dan Desa Purworejo 3611 ind/ha. Sementara untuk kerapatan rata - rata anakan yang ada di ekosistem mangrove di Desa Morodemak sebesar $533 \mathrm{ind} / \mathrm{ha}$ dan Desa Purworejo 1422 ind/ha. Sedangkan untuk kerapatan rata - rata semai yang ada di ekosistem mangrove di Desa Morodemak sebesar 450 ind/ha dan Desa Purworejo 1383 ind/ha. Distribusi kelas diameter pohon di Desa Morodemak dan Desa Purworejo didominasi kelas $<80 \mathrm{~cm}$, sedangkan distribusi tinggi pohon didominasi oleh kelas $10-<14 \mathrm{~m}$.

\section{DAFTAR PUSTAKA}

[IUCN] International Union for Conservation. 2006. Managing Mangroves For Resilience To Climate Change. IUCN, Gland, Switzerland.

Diposaptono, S. 2010. Impacts and Adaptation of Sea Level Rise in Coastal and Small Islands. Proceedings of Workshop Increasing Capacity of Local Scientist for Climate Change Impact and Vulnerability Assesment on Indonesia Archipelago: Workshop in In-Situ/Satellite Sea Level Measurement. Department of Marine Science and Technology. Bogor Agricultural University.

Direktorat Pesisir dan Lautan. 2005. Pedoman Pengelolaan Ekosistem Mangrove. Departemen Kelautan dan Perikanan Direktorat Jendral Kelautan, Pesisir dan Pulau-Pulau Kecil. Jakarta.

Kitamura, S., Anwar, C., Chaniago, A. \& Baba, S. 1997. Handbook of Mangroves in Indonesia. Bali and Lombok. International Society for Mangrove Ecosystem. Denpasar. $199 \mathrm{hlm}$.

Mueller-Dumbois, D. \& Ellenberg, H. 1974. Aims and Methods of Vegetation Ecology. John Willey. London.

Renta, P.P., Pribadi, R., Zainuri, M. \& Utami, M.A.F., 2016. Struktur Komunitas Mangrove di Desa Mojo Kabupaten Pemalang Jawa Tengah. Jurnal Enggano, 1(2):1-10.

Setyawan, A. D. \& Winarno, K. 2006. Permasalahan Konservasi Ekosistem Mangrove di Pesisir Kabupaten Rembang, Jawa Tengah. Biodiversitas, 7(2):159-163.

Soerianegara, I. \& Indrawan, A. 1982. Ekologi Hutan Indonesia. Departemen Manajemen Hutan Fakultas Kehutanan Institusi Pertanian Bogor, Bogor

Tarigan, M.S. 2008. Sebaran dan Luas Hutan Mangrove di Wilayah Pesisir Teluk Pising Utara Pulau Kabaena Sulawesi tenggara. Makara Sains, 12(2):108-112

Tomlinson, P.B. 1994. The Botany of Mangroves. Cambridge University Press, Cambridge, New York. 419 pp. 